\title{
Comparison Between Antenatal Nurses' Compliance With Pregnant Women's Bill of Rights in Urban and Rural Areas in Alexandria
}

\author{
Asmaa Gamal Amer Abd-El salam, B. Sc. N., Faculty of Nursing, Alexandria \\ University,2015.
}

Supervisors:

Prof. Dr. Amany Ahmed Gamal El-Dein Mahmoud

Professor Emeritus of Obstetric \& Gynecologic Nursing faculty of Nursing, Alexandria University

Assist. Prof. Hanan Abd-Elrahman Kandil

Assistant Professor of Obstetric and Gynecologic Nursing Faculty of Nursing,Alexandria University

Assist. Prof. Noha Mohamed Mahmoud

Assistant Professor of Obstetric and Gynecologic NursingFaculty of Nursing,Alexandria University

\begin{abstract}
Background: Pregnancy is one of the most important events that institute a powerful experience in women's life and their families. Pregnant women's relationship with maternity care providers and the maternity care system during pregnancy is vitally important. Care during this period needs to encompass basic human rights. Objective: To compare between nurses' compliance with pregnant women's bill of rights in an urban and rural areas in Alexandria. Settings: The study was carried out at El Shatby Maternity University Hospital and four family medicine centers in Abies, Alexandria. Subjects: A convenient sample of 120 nurses working for at least 2 years in antenatal units of the abovely mentioned settings. Tools: Three tools were used for data collection. The first tool was basic data Questionnaire to identify nurses' socio demographic, academic and professional data. The second tool was nurses' knowledge about pregnant women's bill of rights questionnaire. The third tool was nurses' compliance with pregnant women's bill of rights, observational checklist. Results: Findings of the present study revealed that a statistically significant difference is observed among the two groups regarding the relationship between their total score of knowledge and level of compliance. Although, good knowledge among as much as $51.3 \%$ and $44.0 \%$ of urban and rural nurses, respectively, was associated with poor compliance level. Yet no good compliance was observed among the good knowledge rural ones unlike the urban ones. Where all the good compliant ones were good knowledge ( $\mathrm{p}=0.041)$. Conclusion: The study concluded that nurse's compliance with pregnant women's bill of rights was unfortunately poor in both urban and rural settings. Recommendations: training program(s) are recommended for maternity nurses addressing the importance of compliance with pregnant women's bill of rights.
\end{abstract}

Keywords: Pregnant Women, Bill of Rights 


\section{Introduction}

Pregnancy is a unique period in women's life. It is characterized by complex physiological and hormonal changes (Shagana, J.A., et al.2018). It could be a time of joy and anticipation, yet it could also be a time of discomfort, anxiety and concerns. The role of health care providers in antenatal clinics is crucial here. Where their sensitive respectful interaction with their clients reflects on the pregnant women's safe passage through pregnancy (WHO 2017).

The pregnant women's bill of rights is a guide to ensure full attention to pregnant women's rights and a starting point for the correct definition of the relationship between them and their healthcare providers. The International human rights law includes fundamental commitments of states to enable women to survive pregnancy and childbirth as part of their enjoyment of sexual and reproductive health rights and living a life of dignity (Dehghan et al., 2020).

Pregnant women's relationship with maternity care providers and the maternity care system during pregnancy is vitally important. Care during this period needs to encompass basic human rights, including the rights to respect, dignity, privacy, confidentiality, information and informed consent, the right to the highest attainable standard of health, and non-discrimination and freedom from all forms of illtreatment. A woman's autonomy, choices and preferences should be recognized and respected (Cheng et al.,2020).

Observance of Pregnant women's rights can generate a lot of advantages such as increased quality of health care services, increased ANC utilization, decreased costs, more prompt recovery, decreased length of stay in hospitals, lower risk of irreversible physical and spiritual damages, increased satisfaction of women and healthcare providers as well as improvement in their relationship (Kassa \& Husen, 2019).

Most of the emerging international and regional literature on respectful maternity care revealed that violation of pregnant women's rights is becoming an urgent problem that needs the concern of all stakeholders including health care research, quality and education, human rights and civil rights advocacy worldwide (Tola, Negash, Sileshi, \&Wakgari, 2021). Researches about the observation of pregnant women's bill of rights are scarce in Egypt. Therefore, this study was conducted to evaluate nurses' compliance level with Pregnant Women's Bill of Rights in both urban and rural areas in Alexandria.

\section{Aims of the Study}

1. This study aims to Compare between nurses' compliance with pregnant women's bill of rights in an urban and rural areas in Alexandria.

\section{Research Questions}

Is there a difference in nurses' compliance with pregnant women's bill of rights in an urban and rural areas in Alexandria?

\section{Materials and Method}

Materials

Research design:

A comparative descriptive design was utilized in this study.

\section{Settings:}

The study was carried out at El Shatby Maternity University Hospital (represents an urban area) (in-patient \& out-patient). Four family medicine centers in Abies were randomly selected from the 
ten available centers, namely; Abies 1, Abies 2, Abies 7, and Abies 8

(representing rural areas) (out-patient).

\section{Subjects:}

- The sample size was estimated by using the Epi-Info program, where the following parameters were applied: Prevalence $=50 \%$, Confidence level $=$ $95 \%$, Error level $=5 \%$, sample size $=95$.

- A convenient sample of 120 nurses working for at least 2 years in the abovely mentioned settings and providing direct care for pregnant women. Where all the available nurses at the time of data collection were included in the study.

Tools: In order to collect the necessary data for the study three tools were used:

\section{Tool (I): Basic data Questionnaire:}

This tool was developed by the researcher after thorough review of literature. It is composed of: Nurses' socio demographic, academic and professional data such as: Subject's age, academic level, position, years of experience as well as attendance of training programs.

Tool (II): Nurses' knowledge about pregnant women's bill of rights questionnaire:

It was developed by the researcher based on The Universal Rights of Childbearing Women and the patient's bill of rights in the Egyptian Ministry of Health and Population (MOHP) (White Ribbon Alliance for Safe Motherhood.2011, Abou Zeina, H. $A$, et al .2013). It was used to assess nurses' knowledge about pregnant women's bill of rights. It is comprised of 21 questions grouped in 9 main categories as follows. General knowledge about pregnant women's bill of rights (2 questions); right to privacy(2questions); right to confidentiality (3questions); right to receive information (3 questions), ;right to informed consent (4 questions) ; right to health care (2 questions) ; right to safety (1question) ;right to nondiscrimination (1questions); as well as right to communication (3questions).

Tool (III): Nurses' compliance with pregnant women's bill of rights observational checklist:

This tool was adapted by the researcher from The Universal Rights of Childbearing Women and the patient's bill of rights in the Egyptian Ministry of Health and Population MOHP (White Ribbon Alliance for Safe Motherhood.2011, Abou Zeina, H. A, et al .2013). It entailed 50 items grouped in 8 main categories as follows: Nurse's role regarding the right to privacy (6 items); nurse's role regarding the right to Confidentiality (6 items);nurse's role regarding the right to receive information (8 items); nurse's role regarding the right to informed consent ( 9 items);nurse's role regarding the right to Health care (9 items);nurse's role regarding the right to safety(6items);nurse's role regarding the right to nondiscrimination(1 items) ; as well as nurse's role regarding the right to communication (5 items).

\section{Method:}

- Approval was obtained from the Ethical Research Committee. An official letter from the Faculty of Nursing, University of Alexandria was submitted to the responsible authorities of the previously mentioned settings to carry out the study.

- Tool (II\&III) were adapted by the researcher and translated into Arabic language to suit the Egyptian culture. 
- The three tools were tested for content validity by five experts in the related field. The recommended modifications were done and the final form was finalized after proving valid.

- Tools reliability was accomplished by CRONBACH'S ALPHA test and the result was statistically acceptable $(r=$ 0.95).

- A pilot study was conducted on (12) nurses (excluded from the study subjects) to identify obstacle that might interfere with the process of data collection and calculate the time needed to complete them. Based on the obtained results, the necessary modifications were done.

- Subjects were individually interviewed by the researcher; the purpose of the study was explained and their written consent for participation in the study was obtained.

- Each nurse was observed more than one time (2-4times) until her practice had covered the 8 items in Tool III. These observations were done for each nurse separately during the morning shift (8am to 2pm) in all of the aforementioned settings. In addition to the evening shift (2pm to $8 \mathrm{pm}$ ) in $\mathrm{El}$ Shatby Hospital for 5 days per week over a period of six months, started from the beginning of October 2020 till the end of March 2021.

- After completing the observations through tool III, tool I and II questionnaire were disturbed to all subjects to collect their basic data and to assess their knowledge about pregnant women's bill of rights.

- Data was collected by the researchers during the period from the beginning of October 2020 till the end of March 2021(6 months).

\section{Statistical analysis:}

Collected data were categorized, coded, computerized, tabulated and analyzed using statistical package for social science (SPSS) version 25 and presented in descriptive, and association forms. The necessary tables were then prepared.

\section{Ethical considerations:}

For each recruited subject a written informed consent was obtained after explanation of research purpose and witness written consent from head nurse for observation also was obtained, in addition her privacy, Nurses' voluntary participation and the right to withdraw at any time and confidentiality of her data were all emphasized.

\section{Results}

Table (1) explores that there were almost no statistically significant differences between the subjects'basic data among the two groups. However, such difference was only obvious in relation to place of work whether in-patient or out-patient $(\mathbf{p}=$ $<\mathbf{0 . 0 0 1})$. Most of urban nurses $(82.2 \%)$ and rural ones $(76.7 \%)$ were staff nurses.

Table (2) exhibits that approximately onehalf $(47.8 \%)$ of urban nurses, compared to about two-thirds $(63.3 \%)$ of rural ones had attended antenatal training program(s).

Figure (1) and (2) nurses' level of knowledge about pregnant women's bill of rights were very similar. Where slightly more than one-half of urban nurses $(58 \%)$ and rural ones (53\%), respectively, had good knowledge. Only $7 \%$ and $10 \%$ of urban and rural ones, respectively, had poor knowledge.

Table (3) illustrates the difference between rural and urban nurses' specific knowledge about pregnant women's bill of rights. A statistically significant differences was observed among the two groups in relation to only three out of the nine rights. Firstly, the importance of pregnant women's bill of rights $(\mathrm{p}=0.003)$, where $64.4 \%$ of urban nurses compared to 
only $33.3 \%$ of rural ones had good knowledge about it. Secondly, the right to privacy $(\mathrm{p}=0.008)$, where $85.6 \%$ of urban nurses and only $63.3 \%$ of rural ones had good knowledge about it. Thirdly, the right to health care $(p=0.003)$, where $50 \%$ of urban nurses compared to only $30 \%$ of rural ones had good knowledge regarding this right.

Figure (3) and (4) nurses's compliance with pregnant women's bill of rights was unfortunately poor in both urban settings $(87 \%)$ and rural ones (83\%).Where only $5 \%$ and $17 \%$ of nurses in urban and rural settings, respectively had a fair level of compliance. Consequently, only $8 \%$ of urban nurses had good level of compliance.

Table (4): shows that there was statistically significant difference in relation to only two rights. Firstly, the right to safety $(\mathrm{P}=0.022)$, where $8.9 \%$ of urban nurses compared to $6.7 \%$ of rural ones had good compliance here. Secondly, the right to effective interpersonal communication $(\mathrm{P}=0.028)$, where $12.2 \%$ of urban nurses and $16.7 \%$ of rural ones had good compliance with this right.

Table (5): Shows a statistically significant difference is observed among the two groups regarding the relationship between their total score of compliance and earlier attendance of training programs $(\mathbf{P}=\mathbf{0 . 0 3 0})$.

Table (6): reveals a statistically significant difference among the two groups regarding the relationship between their total score of knowledge and level of compliance ( $\mathbf{P}=\mathbf{0 . 0 4 1})$.

\section{Discussion}

Ensuring universal access to safe, timely, acceptable maternal health care during pregnancy can reduce and prevent the global burden of maternal morbidity and mortality. One of the globally endorsed strategies of combating these huge burdens is the provision of respectful maternity care (RMC), It was primarily established on the principle of providing maternal care with great kindness, dignified, confidential, nondiscriminatory, women-centered and based on the value of human rights throughout the continuum of care (Ishola, Owolabi, \& Filippi, 2017).

Pregnant women's bill of rights is one of the most important ethical considerations in hospitals that need to be addressed (Fazeli, Sedghisabet, Moghadamnia, \& Kazemnejad Leili, 2020). Based on researcher's investigations, few studies had been conducted on compliance with pregnant women's bill of rights, yet no one compared between urban and rural nurses' level of compliance.

The present study's findings revealed a similarity in nurses' level of general knowledge about pregnant women's bill of rights among urban and rural ones. Where more than half of urban and rural nurses had good knowledge about it. This knowledge level is almost similar to the findings of an urban study. El-Shimy, Mostafa, \& Bioumey, (2020). Who had done a study about "Patient's Rights as Perceived by Nurses and Patients, Egypt". They reported that a sizable proportion of staff nurses had good knowledge about patient's bill of rights. The same result is relatively compatible with the findings of a rural study done by Belal, Khalil, \& Elnady, (2017), titled "Impact of Integrated Ethics Program on Nurses Knowledge and Performance at Rural Areas in Fayoum Region, Egypt" they had reported that most of nurses had satisfactory knowledge regarding integrated ethics in the rural areas.

The present study's results could be attributed to the presence of this bill in 
their undergraduate curricula and hospital policy. In addition to the fact that legal and ethical competence is a cornerstone of professional midwifery practice (McDonald, F., \& Then, S.-N book .2019) On the other hand, an urban study reported contradictory findings in this respect. Hajifoghaha, M. et al. (2020), who had conducted a study to investigate the educational needs of midwives in Iran. Their findings have shown that midwives have various educational needs one of them is pregnant women's rights. Also, there was a study done on rural resident nurses reported contradictory findings in this respect. This study was conducted by Hassan, Mansour, \& Aboud, (2019), titled "Effect of an Educational Program on Enhancing Nurses' Knowledge and Their Compliance with Ethics in Maternity Health Services in Mansoura, Egypt" they had reported that the majority of rural nurses had a highly significant improvement post-intervention compared to pre-intervention regarding nurse's knowledge about nursing ethics at the maternity health services. Where only about one quarter of nurses had good knowledge.

In the present study there was a statistically significant difference among urban and rural nurses' knowledge regarding three rights. Firstly: the importance of pregnant women's bill of rights. Secondly: the right to privacy. Thirdly: the right to health care. It's interesting to notice that the difference in the knowledge about these three rights was in favor of the urban group. this could be explained by the fact that most of the urban ones were working in in-patient department unlike all the rural ones who were out-patient employees, where policies, guidelines and standards are not usually cleared and utilized.

The present study's findings revealed a similarity in nurses' level of compliance with pregnant women's bill of rights among urban and rural ones. Where the majority of urban and rural nurses had poor compliance with pregnant women's bill of rights. This low level of compliance among both rural and urban subjects in the current study is in accordance with the findings of an urban study done by Hameed, Uddin, \& Avan, (2021). titled "Are underprivileged and less empowered women deprived of respectful maternity care in Pakistan", They reported that all maternity nurses had poor compliance with pregnant women's bill of rights. Specifically, the right to effective communication. In addition, this result is in accordance with the finding of two rural studies Firstly: the previously mentioned study done on rural resident nurses which was conducted by Hassan, Mansour, \& Aboud, (2019). They revealed that the majority of rural nurses had poor compliance with ethics in maternity health services. Secondly: the previously mentioned study done by Belal, Khalil \& EInady, (2017). They reported that $68 \%$ of rural nurses had poor compliance with integrated ethics in M.C.H centers.

This poor compliance could be attributed to multifactor. Firstly: health settings management system or regulation such as inadequate guidance and supervision of nurses' practice. Beside inadequate policy and procedure, lack of accountability and limited legal redress mechanisms, shortage of nursing staff, limited budget and facilities. Secondly: health care providers (nurses), where their low level of compliance -without doubt- is related to lack of adequate knowledge and positive attitude towards pregnant women's rights. Beside inadequate training programs.

On the other hand, this same result of the present study is contradicting with the findings of an urban study conducted by Nasiriani, Rahimparvar, Farajkhoda, \& Bahrani, (2018) titled "The related factors of compliance to professional 
codes of ethics from midwives' perspective working in healthcare centers (HCCs) of Tehran, Iran". They reported that compliance with pregnant women's rights by midwives in governmental HCCs of Tehran was at a good level. Where $95 \%$ of midwives had good compliance.

There is also a study done on rural resident nurses that reported a contradictory finding in this respect. It was conducted by Fouad, Abdelrahman, \& Mohamed, (2020), titled "Nurses Compliance Toward Patients' Rights and its Relation to Patients Satisfaction in Minia, Egypt". They revealed that slightly more than half of staff nurses at Minia University Hospital had high level of compliance toward patients' rights. While about half of them had moderate level of compliance during the three times observation. Such discrepancy between the results of this study and the present study's findings could be attributed to the earlier's setting where it was done in a general hospital while the present study was done in maternity settings which had usually increased turnover of maternal cases.

The findings of the present study revealed a statistically significant difference among urban and rural nurses regarding the relationship between their total score of knowledge and level of compliance with pregnant women's bill of rights. Where all good compliant urban nurses were good knowledged. While no good compliance among good knowledged rural ones was observed. However, most of good knowledged nurses among the two groups were associated with poor compliance level. Consequently, there was no statistically significant difference between all of the present study subject's total score of knowledge and level of compliance with pregnant women's bill of rights. This result is in accordance with the finding of an urban study done by Nekoei, Amiresmaeili, Ghorbaninia, Sharifi, \& Tabatabaie, (2014), titled "Awareness of
Patients' rights Charter and Respecting It from The Perspective of Patients and Nurses: A Study of Limited Surgical Centers in Kerman City, Iran 2013". They reported that despite their nurses' good level of knowledge, their compliance level was not good. Hence, concluded that there was no statistically significant relation between their study subjects's total score of knowledge and their total score of compliance with Patients' bill of rights.

This finding also contradicts with the findings of an urban study done by Shaali \& Shahriari, (2018), titled "Evaluation of compliance rate of midwives with the codes of professional ethics in maternity and gynecology wards of hospitals affiliated with Isfahan University of Medical Sciences, Iran". They reported a direct association between the mean score of compliance with the ethical codes and knowledge about the midwifery codes of professional ethics.

Generally speaking, good knowledge among all of the present study subjects was associated with poor compliance level. Such result may be attributed to the fact that almost one-half of nurses in the two groups had got information about pregnant women's bill of rights only from their undergraduate curricula. Usually this issue receive not enough attention in the undergraduate education. Most of the study subjects in either urban or rural settings had inadequate number of relevant training programs. Where most of them had attended only one training program in this respect.

\section{Conclusion}

Based on the findings of the present study, it can be concluded that a statistically significant difference was noticed among the two groups regarding the relationship between their total score of knowledge and level of compliance. Where no good compliance was observed among the good knowledge rural nurses 
while all good compliant urban ones were good knowledge. However, nurse's compliance with pregnant women's bill of rights was unfortunately poor in both urban and rural settings.

\section{Recommendations}

Based on the findings of the present study, the following recommendations are suggested:

1. Pre-service and in- service training program(s) are recommended for maternity nurses addressing the importance of compliance with pregnant women's bill of rights.

2. Continuous monitoring of antenatal nurses' awareness and compliance with pregnant women's bill of rights is suggested.

3. Arabic posters about pregnant women's rights are better to be available and visible to all nurses in maternity hospitals.

4. An ethical committee is recommended to be implemented at maternity health settings to monitor nurses' adherence with pregnant women's bill of rights. 
Table (1): Comparison between nurses in the two studied groups according to their basic data.

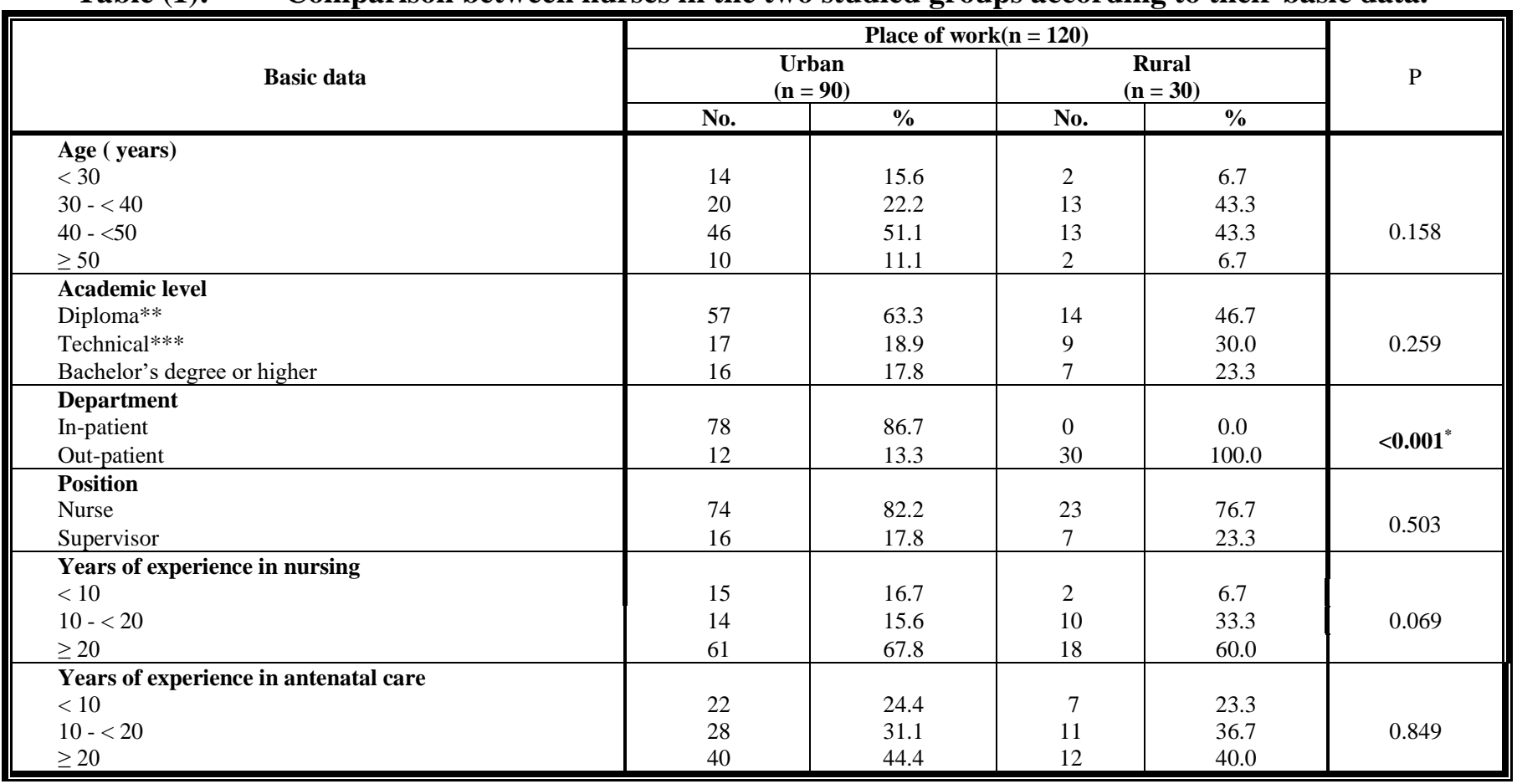

Table (2): Comparison between nurses in the two studied groups according to their attendance of antenatal training programs.

\begin{tabular}{|c|c|c|c|c|c|}
\hline \multirow{3}{*}{ Training programs } & \multicolumn{4}{|c|}{ Place of work $(n=120)$} & \multirow{3}{*}{$\mathbf{P}$} \\
\hline & \multicolumn{2}{|c|}{$\begin{array}{c}\begin{array}{c}\text { Urban } \\
(n=90)\end{array} \\
\end{array}$} & \multicolumn{2}{|c|}{$\begin{array}{c}\text { Rural } \\
(n=30)\end{array}$} & \\
\hline & No. & $\%$ & No. & $\%$ & \\
\hline \multicolumn{6}{|l|}{ Attendance : } \\
\hline Yes & 43 & 47.8 & 19 & 63.3 & 0.140 \\
\hline Number of attained programs & \multicolumn{2}{|c|}{$(n=43)$} & \multicolumn{2}{|c|}{$(n=19)$} & \multirow{4}{*}{0.342} \\
\hline 1 & 35 & 81.4 & 14 & 73.7 & \\
\hline 2 & 8 & 18.6 & 4 & 21.1 & \\
\hline 3 & 0 & 0.0 & 1 & 5.3 & \\
\hline Duration since last program & \multicolumn{2}{|c|}{$(n=43)$} & \multicolumn{2}{|c|}{ (n=19) } & \multirow{5}{*}{0.065} \\
\hline$<3$ yrs. & 2 & 4.7 & 5 & 26.3 & \\
\hline $3-<6$ yrs. & 21 & 48.8 & 5 & 26.3 & \\
\hline $6-<9$ yrs. & 6 & 14.0 & 2 & 10.5 & \\
\hline$\geq 9$ yrs. & 14 & 32.6 & 7 & 36.8 & \\
\hline Agency provided the program & \multicolumn{2}{|c|}{$(n=43)$} & \multicolumn{2}{|c|}{$(n=19)$} & \multirow{3}{*}{$<0.001^{*}$} \\
\hline Ministry of health & 11 & 25.6 & 19 & 100.0 & \\
\hline University & 32 & 74.4 & 0 & 0.0 & \\
\hline
\end{tabular}

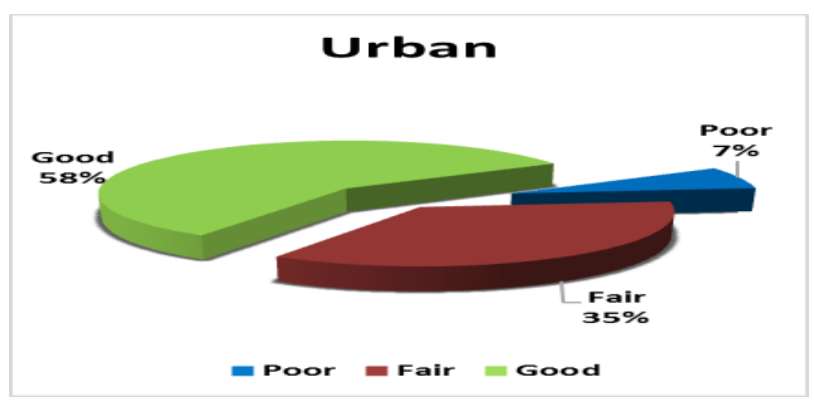

Figure (1): Percent distribution of nurses in Urban area according to their total score of knowledge about pregnant women's bill of rights. 


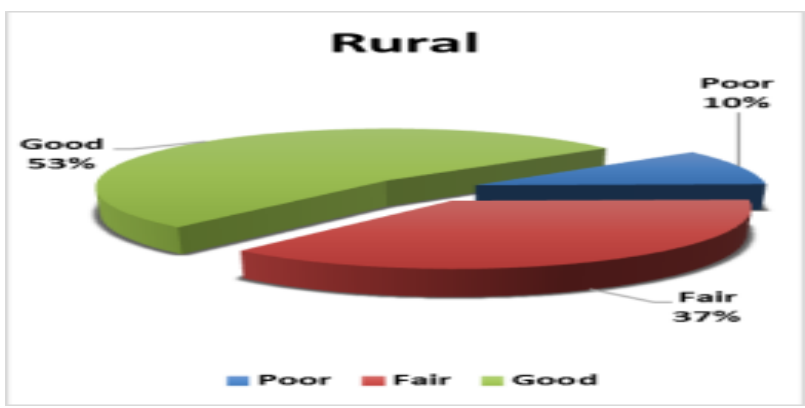

Figure (2): Percent distribution of nurses in Rural areas according to their total score of knowledge about pregnant women's bill of rights.

Table (3): Comparison between nurses in the two studied groups according to their specific knowledge about pregnant women's bill of rights.

\begin{tabular}{|c|c|c|c|c|c|c|c|c|c|c|c|c|c|}
\hline \multirow{4}{*}{ Pregnant women's rights } & \multicolumn{12}{|c|}{ Place of work $(n=120)$} & \multirow{4}{*}{$\mathbf{P}$} \\
\hline & \multicolumn{6}{|c|}{ Urban (n = 90) } & \multicolumn{6}{|c|}{ Rural $(\mathbf{n}=\mathbf{3 0})$} & \\
\hline & \multicolumn{2}{|c|}{ Poor } & \multicolumn{2}{|c|}{ Fair } & \multicolumn{2}{|c|}{ Good } & \multicolumn{2}{|c|}{ Poor } & \multicolumn{2}{|c|}{ Fair } & \multicolumn{2}{|c|}{ Good } & \\
\hline & No. & $\%$ & No. & $\%$ & No. & $\%$ & No. & $\%$ & No. & $\%$ & No. & $\%$ & \\
\hline $\begin{array}{l}\text { 1-The importance of pregnant } \\
\text { women's rights }\end{array}$ & 0 & 0.0 & 32 & 35.6 & 58 & 64.4 & 0 & 0.0 & 20 & 66.7 & 10 & 33.3 & $0.003^{*}$ \\
\hline 2- The right to safety & 1 & 1.1 & 36 & 40.0 & 53 & 58.9 & 0 & 0.0 & 11 & 36.7 & 19 & 63.3 & 0.868 \\
\hline 3- The right to Information & 5 & 5.6 & 40 & 44.4 & 45 & 50.0 & 4 & 13.3 & 14 & 46.7 & 12 & 40.0 & 0.315 \\
\hline-4 The right to Informed consent & 11 & 12.2 & 39 & 43.3 & 40 & 44.4 & 3 & 10.0 & 10 & 33.3 & 17 & 56.7 & 0.508 \\
\hline 5- The right to Privacy & 0 & 0.0 & 13 & 14.4 & 77 & 85.6 & 0 & 0.0 & 11 & 36.7 & 19 & 63.3 & $0.008^{*}$ \\
\hline 6- The right to Confidentiality & 2 & 2.2 & 48 & 53.3 & 40 & 44.4 & 0 & 0.0 & 10 & 33.3 & 20 & 66.7 & 0.125 \\
\hline 7- The right to nondiscrimination & 26 & 28.9 & 22 & 24.4 & 42 & 46.7 & 11 & 36.7 & 6 & 20.0 & 13 & 43.3 & 0.709 \\
\hline 8- The right to Health care & 11 & 12.2 & 34 & 37.8 & 45 & 50.0 & 12 & 40.0 & 9 & 30.0 & 9 & 30.0 & $0.003^{*}$ \\
\hline $\begin{array}{l}\text { 9- The right to effective interpersonal } \\
\text { communication }\end{array}$ & 2 & 2.2 & 37 & 41.1 & 51 & 56.7 & 2 & 6.7 & 15 & 50.0 & 13 & 43.3 & 0.244 \\
\hline
\end{tabular}

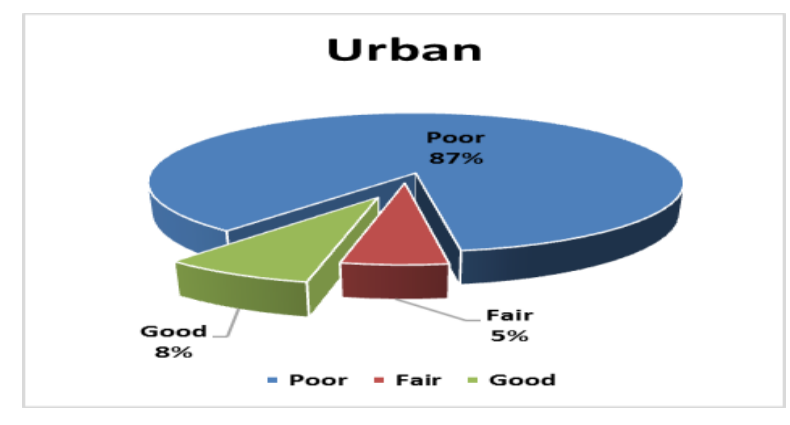

Figure (3): Percent distribution of nurses in Urban area according to their total score of compliance with pregnant women's bill of rights.

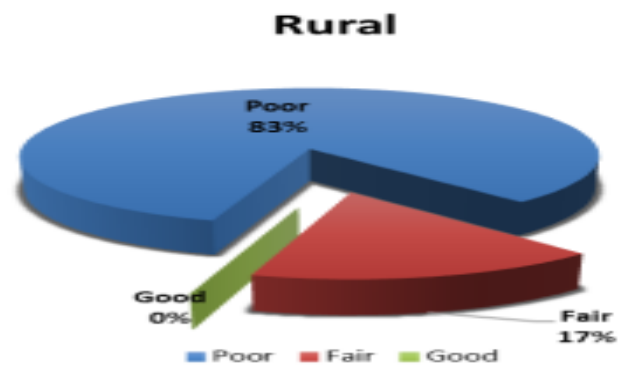

Figure (4): Percent distribution of nurses in Rural areas according to their total score of compliance with pregnant women's bill of rights. 
Table (4): Comparison between nurses in the two studied groups according to their specific compliance with pregnant women's bill of rights.

\begin{tabular}{|c|c|c|c|c|c|c|c|c|c|c|c|c|c|}
\hline \multirow{4}{*}{ Nurses' compliance level } & \multicolumn{12}{|c|}{ Place of work $(n=120)$} & \multirow{4}{*}{$\mathbf{P}$} \\
\hline & \multicolumn{6}{|c|}{ Urban $(\mathbf{n}=90)$} & \multicolumn{6}{|c|}{ Rural $(\mathbf{n}=\mathbf{3 0})$} & \\
\hline & \multicolumn{2}{|c|}{ Poor } & \multicolumn{2}{|c|}{ Fair } & \multicolumn{2}{|c|}{ Good } & \multicolumn{2}{|c|}{ Poor } & \multicolumn{2}{|c|}{ Fair } & \multicolumn{2}{|c|}{ Good } & \\
\hline & No. & $\%$ & No. & $\%$ & No. & $\%$ & No. & $\%$ & No. & $\%$ & No. & $\%$ & \\
\hline 1- The right to safety & 61 & 67.8 & 21 & 23.3 & 8 & 8.9 & 13 & 43.3 & 15 & 50.0 & 2 & 6.7 & $0.022^{*}$ \\
\hline 2- The right to Information & 75 & 83.3 & 8 & 8.9 & 7 & 7.8 & 21 & 70.0 & 7 & 23.3 & 2 & 6.7 & 0.138 \\
\hline 3- The right to Informed consent & 54 & 60.0 & 27 & 30.0 & 9 & 10.0 & 16 & 53.3 & 12 & 40.0 & 2 & 6.7 & 0.567 \\
\hline 4- The right to Privacy & 47 & 52.2 & 33 & 36.7 & 10 & 11.1 & 18 & 60.0 & 7 & 23.3 & 5 & 16.7 & 0.367 \\
\hline 5- The right to Confidentiality & 48 & 53.3 & 34 & 37.8 & 8 & 8.9 & 11 & 36.7 & 18 & 60.0 & 1 & 3.3 & 0.092 \\
\hline 6- The right to nondiscrimination & 46 & 51.1 & 31 & 34.4 & 13 & 14.4 & 21 & 70.0 & 5 & 16.7 & 4 & 13.3 & 0.148 \\
\hline 7- The right to Health care & 6 & 6.7 & 72 & 80.0 & 12 & 13.3 & 1 & 3.3 & 24 & 80.0 & 5 & 16.7 & 0.852 \\
\hline $\begin{array}{l}\text { 8- The right to effective } \\
\text { interpersonal communication }\end{array}$ & 28 & 31.1 & 51 & 56.7 & 11 & 12.2 & 2 & 6.7 & 23 & 76.7 & 5 & 16.7 & $0.028^{*}$ \\
\hline
\end{tabular}

Table (5): Comparison between the two study groups regarding the relationship between their total score of compliance and attendance of training programs.

\begin{tabular}{|c|c|c|c|c|c|c|c|c|c|c|c|c|c|}
\hline \multirow{4}{*}{ Training programs } & \multicolumn{12}{|c|}{ Total score of compliance with pregnant women's bill of rights } & \multirow{4}{*}{$\mathbf{P}$} \\
\hline & \multicolumn{6}{|c|}{ Urban $(\mathbf{n}=90)$} & \multicolumn{6}{|c|}{ Rural $(\mathrm{n}=30)$} & \\
\hline & \multicolumn{2}{|c|}{$\begin{array}{c}\text { Poor } \\
(\mathrm{n}=78)\end{array}$} & \multicolumn{2}{|c|}{$\begin{array}{c}\text { Fair } \\
(\mathbf{n}=5)\end{array}$} & \multicolumn{2}{|c|}{$\begin{array}{c}\text { Good } \\
(\mathbf{n}=7)\end{array}$} & \multicolumn{2}{|c|}{$\begin{array}{c}\text { Poor } \\
(\mathbf{n}=25)\end{array}$} & \multicolumn{2}{|c|}{$\begin{array}{c}\text { Fair } \\
(\mathbf{n}=\mathbf{5})\end{array}$} & \multicolumn{2}{|c|}{$\begin{array}{c}\text { Good } \\
(\mathbf{n}=\mathbf{0})\end{array}$} & \\
\hline & No. & $\%$ & No. & $\%$ & No. & $\%$ & No. & $\%$ & No. & $\%$ & No. & $\%$ & \\
\hline $\begin{array}{c}\text { Attendance : } \\
\text { Yes }\end{array}$ & 34 & 43.6 & 2 & 40.0 & 7 & 100 & 15 & 60.0 & 4 & 80.0 & 0 & 0.0 & $0.030^{*}$ \\
\hline No & 44 & 56.4 & 3 & 60.0 & 0 & 0.0 & 10 & 40.0 & 1 & 20.0 & 0 & 0.0 & 1.000 \\
\hline \multicolumn{14}{|l|}{$\begin{array}{c}\text { Number of attained } \\
\text { programs }\end{array}$} \\
\hline 1 & 29 & 85.3 & 2 & 100 & 4 & 57.1 & 12 & 80.0 & 2 & 50.0 & 0 & 0.0 & 0.377 \\
\hline 2 & 5 & 14.7 & 0 & 0.0 & 3 & 42.9 & 3 & 20.0 & 1 & 25.0 & 0 & 0.0 & 0.180 \\
\hline 3 & 0 & 0.0 & 0 & 0.0 & 0 & 0.0 & 0 & 0.0 & 1 & 25.0 & 0 & 0.0 & - \\
\hline \multicolumn{14}{|l|}{$\begin{array}{c}\text { Duration since last } \\
\text { program }\end{array}$} \\
\hline$<3$ yrs. & 1 & 2.9 & 0 & 0.0 & 1 & 14.3 & 4 & 26.7 & 1 & 25.0 & 0 & 0.0 & 0.519 \\
\hline $3-<6$ yrs. & 16 & 47.1 & 1 & 50.0 & 4 & 57.1 & 4 & 26.7 & 1 & 25.0 & 0 & 0.0 & 0.468 \\
\hline $6-<9$ yrs. & 4 & 11.8 & 1 & 50.0 & 1 & 14.3 & 2 & 13.3 & 0 & 0.0 & 0 & 0.0 & 1.000 \\
\hline$\geq 9$ yrs. & 13 & 38.2 & 0 & 0.0 & 1 & 14.3 & 5 & 33.3 & 2 & 50.0 & 0 & 0.0 & 0.101 \\
\hline \multicolumn{14}{|l|}{$\begin{array}{c}\text { Agency provided the } \\
\text { program }\end{array}$} \\
\hline Ministry of health & 11 & 32.4 & 0 & 0.0 & 0 & 0.0 & 15 & 100 & 4 & 100 & 0 & 0.0 & 0.268 \\
\hline University & 23 & 67.6 & 2 & 100 & 7 & 100 & 0 & 0.0 & 0 & 0.0 & 0 & 0.0 & - \\
\hline
\end{tabular}


Table (6): Comparison between the two study groups regarding the relationship between their total score of compliance with pregnant women's bill of rights and total score of knowledge about it.

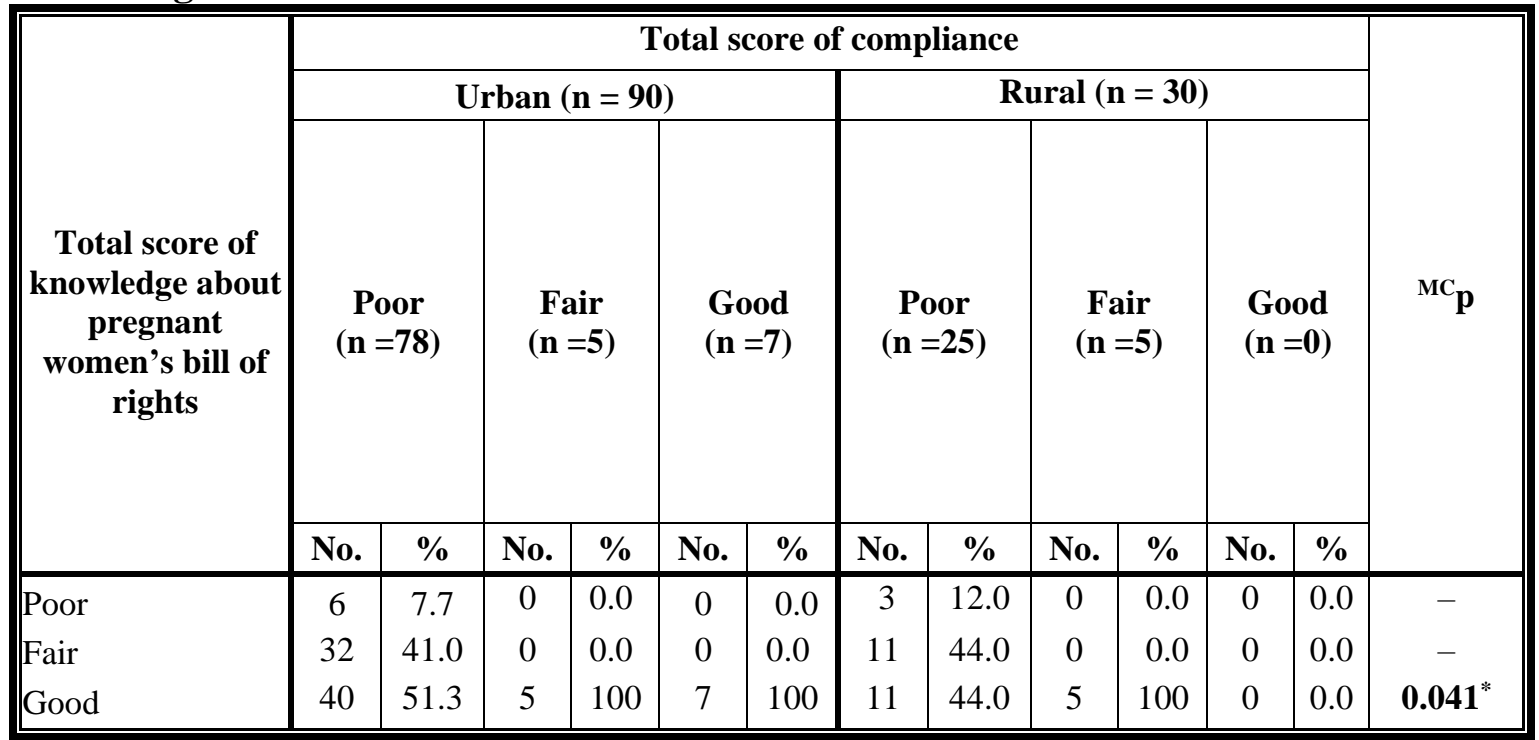




\section{Referen}

- Abou Zeina, H.A., El Nouman, A.A., Zayed,M.A.,Hifnawy,T.,

Shabrawy,E.M.,\& El Tahlawy,E.(2013). Patients' rights: a hospital survey in South Egypt. Journal of Empirical Research on Human Research Ethics,8(3),46- 52.

- Belal, S., Khalil, H. H. S., \& Elnady, F. M. (2017). Impact of integrated ethics program on nurses' knowledge and performance at rural areas in Fayoum region, Egypt. American Journal of Nursing, 6(3), 240-250.

- Cheng, E. R., Carroll, A. E., Iverson, R. E., \& Declercq, E. R. (2020). Communications between pregnant women and maternity care clinicians. JAMANetworkOpen,3(5),1-4.

- Dehghan, M., Mehdipour-Rabori, R., Rayani, M., Zakeri, M. A., Mobasher, M., Iranmanesh, M., \& Rezai, N. (2020). Comparison of the importance and observance of the patient's bill of rights from the perspectives of patients and personnel of hospitals in Kerman. Journal of medical ethics and history of medicine, 13(5),1-14.

- El-Shimy, H, M., Mostafa, H, A., \& Bioumey, M, H. (2020). Patient's Rights as Perceived by Nurses and Patients. Egyptian Journal of Health Care,11(1), 73-81.

- $\quad$ Fazeli, S. N., Sedghisabet, M., Moghadamnia, M. T., \& Kazemnejad Leili, E. (2020). The Status of Observing the Charter of Patients' Rights and Related Factors from the Point of View of Hospitalized Patients. Journal of Holistic Nursing and Midwifery, 30(3), 144-150.

- Fouad, E. R., Abdelrahman, S. M., \& Mohamed, E. A. (2020). Nurses Compliance Toward Patients' Rights and its Relation to Patients Satisfaction. Minia Scientific Nursing Journal,7(1), 44-53.
- Hajifoghaha, M., Nahidi, F., Alizadeh, S., Golezar, S., Dabiri, F., Mokhlesi, S. S., \& Babaei, A. (2020). Midwives' Educational Needs in Iran: A Narrative Review. Iranian journal of nursing and midwifery research, 25(1), 1-12.

- Hameed, W., Uddin, M., \& Avan, B. I. (2021). Are underprivileged and less empowered women deprived of respectful maternity care: Inequities in childbirth experiences in public health facilities in Pakistan. Plos one, 16(4),117.

- Hassan, S. I., Mansour, S. E. S., \& Aboud, S. A. H. H. (2019). Effect of an Educational Program on Enhancing Nurses' Knowledge and Their Compliance with Ethics in Maternity Health Services. American Journal of Nursing, 7(5), 697-706.

- Ishola, F., Owolabi, O., \& Filippi, V. (2017). Disrespect and abuse of women during childbirth in Nigeria: a systematic review. PloS one,12(3),1-17.

- Kassa, Z. Y., \& Husen, S. (2019). Disrespectful and abusive behavior during childbirth and maternity care in Ethiopia: a systematic review and metaanalysis. BMC research notes, 12(1),1-6.

- McDonald, F., \& Then, S.-N. (2019). Ethics, law and health care: A guide for nurses and midwives. 2 nd ed. the united states.

- Nasiriani, L., Rahimparvar, S. F. V., Farajkhoda, T., \& Bahrani, N. (2018). The related factors of compliance to professional codes of ethics from midwives' perspective working in healthcare centers of Tehran-Iran. The Pan African Medical Journal, 30(40),111.

- $\quad$ Nekoei, M. M., Amiresmaeili, M. R., Ghorbaninia, R., Sharifi, T., \& Tabatabaie, S. (2014). Awareness of Patients' rights Charter and Respecting It from The Perspective Of Patients And 
Nurses: A Study Of Limited Surgical Centers In Kerman City. Journal Of Bioethics, 4(11),31-56.

- Shaali, M., \& Shahriari, M. (2018).

Evaluation of compliance rate of midwives with the codes of professional ethics in maternity and gynecology wards of hospitals affiliated with Isfahan University of Medical Sciences in 2016. The Iranian Journal of Obstetrics, Gynecology and Infertility, 21(3), 54-63.

- Shagana, J.A., Dhanraj, M., Jain, A.R., \& Nirosa, T. (2018). Physiological changes in pregnancy. Drug Invention Today. 10(8),1594-1597.

- Tola, W., Negash, E., Sileshi, T., \&Wakgari, N .(2021). Late initiation of antenatal care and associated factors among pregnant women attending antenatal clinic of Ilu Ababor Zone, southwest Ethiopia: A cross-sectional study. PLoS ONE,16(1),1-11.

- White Ribbon Alliance (WRA). (2011). The respectful maternity care charter: The universal rights of childbearing women.

Washington.AvailableatURL:https://ww w.whiteribbonalliance.org/respectfulmaternity-care-charter/ Accessed in Oct 2021.

- World Health Organization. (2017). Managing complications in pregnancy and childbirth: A guide for midwives and doctors. (2nd ed).

Geneva. 